\title{
Caridina nilotica in Lake Victoria: abundance, biomass, and diel vertical migration
}

\author{
John T. Lehman', Godfrey B. Mbahinzireki² \& Lucas Mwebaza-Ndawula ${ }^{2}$ \\ ${ }^{1}$ Department of Biology and Center for Great Lakes and Aquatic Science, Natural Science Building, University of \\ Michigan, Ann Arbor, MI 48109, USA \\ ${ }^{2}$ Uganda Fisheries Research Institute, P.O. Box 343, Jinja, Uganda
}

Received 28 September 1994; in revised form 7 February 1995; accepted 16 February 1995

Key words: zooplankton biomass, Lake Victoria, diel vertical migration, Caridina, Chaoborus

\begin{abstract}
Caridina nilotica (Decapoda: Atyidae) in offshore waters of Lake Victoria were investigated with both day and night sampling over a period of two years. Offshore populations are mainly planktonic rather than benthic, and the animals exhibit diel vertical migrations into near-surface waters at night. These changes in diel abundance as well as the size-frequency distribution of the migrating shrimp suggest that the migratory behavior is in response to visual planktivory, because only the very smallest individuals $(2-4 \mathrm{~mm})$ remain in surface waters during the day. During October 1992, abundances were estimated both by vertical net sampling and by underwater video transect methods. Concordance was established between abundances estimated by the two methods. Only about 9\% (night) to $14 \%$ (day) of the Caridina population appeared to be epibenthic. We suggest that the behavior of the animal is consistent with the hypothesis that it is not a strict detritivore as previously reported; rather it may engage in facultative planktivory, especially at night.
\end{abstract}

\section{Introduction}

Freshwater prawns (Decapoda) from both the Atyidae (Caridina, Limnocaridina) and Palaemonidae (Macrobrachium) are common in the Great Lakes of East Africa (Beadle, 1981). In Lake Victoria, the predominant species is Caridina nilotica, which can attain maximum adult lengths of $c .2 .5 \mathrm{~cm}$ (Fryer, 1960). C. niloti$c a$ is an important forage item for juvenile and subadult Nile perch up to $40 \mathrm{~cm}$ length (Ogutu-Ohwayo, 1990), and it occurs in significant proportions in diets of fish up to $80 \mathrm{~cm}$ (Hughes, 1992). Caridina has been characterized as an epibenthic detritivore, mainly on the basis of gut content analyses of littoral specimens and laboratory observation of feeding behavior (Fryer, 1960). Fryer characterized the taxon as ' $w i t h o u t$ doubt benthic and not pelagic in habit' (p. 219), but even from the earliest ecological surveys, atyid shrimps have been encountered in the plankton (Worthington, 1931).

Fryer (1960) characterized Caridina as a chelate raptatory feeder, and although in his experience the diet was almost entirely detritus, the animals have a morphology that would permit feeding on larger living particles. The presence of a gastric mill at the base of the esophagus makes morphological studies of the gut contents relatively unrevealing, however, because ingested food items are immediately ground to a homogeneous paste. Setae and other parts of microcrustacean exoskeletons are present in the guts (personal observation), but it is not possible to tell by inspection whether the animals were intact and alive when ingested.

The offshore plankton community of Uganda waters of Lake Victoria has been the subject of several recent investigations (Lehman \& Branstrator, 1993; Mugidde, 1993; Mwebaza-Ndawula, 1994; Branstrator et al., in press). During some of these studies it was possible to make both day and night observations of the abundance and vertical distribution of Caridina nilotica. In this paper we report these ecological observations as well as the first biomass estimates for the 
shrimp in order to permit comparison with the biomass of other zooplankton in the lake.

\section{Materials and methods}

\section{Net collections}

Plankton collections for estimation of vertical distributions were obtained with a $0.5-\mathrm{m}$ diameter net of 5:1 aspect ratio fitted with $100 \mu \mathrm{M}$ aperture nylon mesh (Research Nets, Inc.) and a non-filtering PVC codend. The net was equipped with a harness to permit the suspension of weights below the net so that vertical orientation could be maintained in all current regimes. Replicate collections were made while the ship lay at anchor by repeatedly lowering the net to depth and drawing it vertically at $c .0 .5 \mathrm{~m} \mathrm{~s}^{-1}$. Typically 4 replicate tows were obtained at each sampling. For studies of diel migration, the replicates were counted individually to characterize sampling variability. Branstrator et al. (in press) have described subsampling and counting methods for the microcrustacean zooplankton. For Caridina and Chaoborus, all specimens in either a onehalf or one-quarter split of the original sample were enumerated.

Additional net collections for assessment of abundance and biomass were obtained with a $1 \mathrm{~m}^{2}$ frame net (Nero, 1982). All the Caridina from each collection, or from a one-half split of the collection, were measured to the nearest $1 \mathrm{~mm}$ (midpoint of eyes to base of telson). Representative specimens of different length were rinsed in deionized water and were dried to constant mass at $60^{\circ} \mathrm{C}$ for dry mass determination (Cahn Model 29 electrobalance).

\section{Mid-water video transects}

Independent estimates of abundance for Caridina nilotica were obtained with a remotely operated vehicle (ROV) equipped with an $8 \mathrm{~mm}$ video camera and collimated red light source (Lee \& Hall, 1989). The ROV was deployed 28 October 1992 while the surface ship (R/V Imputa) lay at anchor in offshore waters of Lake Victoria $\left(0^{\circ} 3.16^{\prime} \mathrm{S}, 33^{\circ} 16.59^{\prime} \mathrm{E}\right)$, south of Bugaia Island, Uganda at $64 \mathrm{~m}$ depth. Mid-water video transects were obtained $c .50$ to $100 \mathrm{~m}$ starboard and parallel to the anchor line at multiple depths both day and night.

The intersection of the collimator and the video field sampled a 8.91 volume (D. Lee, personal communication), in which all Caridina, as well as many smaller zooplankton were distinguishable. Preliminary trials established that Caridina reacted adversely to the light source, and as a consequence, transects were conducted with only intermittent illumination. The ROV was moved at constant speed, at constant depth, and on a fixed compass heading parallel to the ship for $5 \mathrm{sec}$ in darkness, and then the collimator was switched on for $2 \mathrm{sec}$. The sequence was repeated from 26 to 134 times at each depth. Whenever the ROV approached the end of a mid-water transect, two minutes running time, it was turned $180^{\circ}$ to starboard or port away from the surface ship so that replicate transects were taken at progressively greater distances from the ship.

Data were extracted from the video tapes visually. Tapes were played on an $8 \mathrm{~mm}$ Sony GV-500 VCR and video was displayed both on the GV-500 color LCD and on a remote color CRT monitor. The video frame was paused within the first second of illumination, as soon as the video image stabilized in response to the light source, and all Caridina present in the illuminated volume of lake water were counted.

\section{Bottom video transects}

Video transects along the lake bottom were similarly conducted both day and night, at the conclusion of the mid-water transects. The ROV was maneuvered along linear transects with its basal support frame resting on the bottom, and with its camera a fixed distance above the flat mud surface. An area of bottom equivalent to $12.7 \mathrm{~cm}$ by $25.4 \mathrm{~cm}$ was traced to scale on the video CRT screen based on the illuminated profile of the collimator projected on the sediment surface. By geometric scaling, an area representing $64 \mathrm{~cm}^{2}$ of the bottom surface was traced on the video screen. During video replay, the frame was paused every $5 \mathrm{sec}$, an interval long enough to guarantee non-overlapping and non-adjacent fields, and all Caridina within the scaled video quadrant were counted.

\section{Results}

\section{Length-weight regression and wet weight conversions}

The empirical relationship between individual Caridina length $(1, \mathrm{~mm})$, measured from midpoint of the eyes to the base of the telson, and dry mass (DW, $\mu \mathrm{g}$ ) was established by nonlinear regression $\left(r^{2}=0.989, n=81\right.$; SYSTAT 5.0): 
Table 1. Frequency distributions of Caridina nilotica determined by ROV mid-water video transects on 28 October 1992 . Data columns contrast relative frequencies of encountering from 0 to 7 individual Caridina in 8.91 illuminated volumes of lake water along mid-water transects at constant depth.

\begin{tabular}{|c|c|c|c|c|c|c|c|c|c|c|}
\hline \multirow{2}{*}{$\begin{array}{l}\text { Caridina per } \\
8.91 \text { field }\end{array}$} & \multicolumn{2}{|c|}{$10 \mathrm{~m}$} & \multicolumn{2}{|l|}{$20 \mathrm{~m}$} & \multicolumn{2}{|l|}{$40 \mathrm{~m}$} & \multicolumn{2}{|l|}{$50 \mathrm{~m}$} & \multicolumn{2}{|l|}{$60 \mathrm{~m}$} \\
\hline & Day & Night & Day & Night & Day & Night & Day & Night & Day & Night \\
\hline 0 & 1 & 0.930 & 1 & 0.840 & 0.984 & 0.919 & 0.985 & 0.870 & 0.213 & 0.917 \\
\hline 1 & 0 & 0.070 & 0 & 0.127 & 0.015 & 0.080 & 0.014 & 0.129 & 0.262 & 0.074 \\
\hline 2 & 0 & 0 & 0 & 0.021 & 0 & 0 & 0 & 0 & 0.245 & 0.007 \\
\hline 3 & 0 & 0 & 0 & 0.010 & 0 & 0 & 0 & 0 & 0.163 & 0 \\
\hline 4 & 0 & 0 & 0 & 0 & 0 & 0 & 0 & 0 & 0.049 & 0 \\
\hline 5 & 0 & 0 & 0 & 0 & 0 & 0 & 0 & 0 & 0.049 & 0 \\
\hline 6 & 0 & 0 & 0 & 0 & 0 & 0 & 0 & 0 & 0 & 0 \\
\hline 7 & 0 & 0 & 0 & 0 & 0 & 0 & 0 & 0 & 0.016 & 0 \\
\hline $\mathrm{N}$ (fields) & 26 & 71 & 94 & 94 & 65 & 87 & 68 & 116 & 61 & 134 \\
\hline Mean & 0 & 0.070 & 0 & 0.202 & 0.015 & 0.080 & 0.014 & 0.129 & 1.803 & 0.089 \\
\hline Variance & 0 & 0.061 & 0 & 0.233 & 0.014 & 0.068 & 0.014 & 0.098 & 1.596 & 0.089 \\
\hline Caridina $\mathrm{m}^{-3}$ & 0 & 7.9 & 0 & 22.7 & 1.7 & 9.0 & 1.7 & 14.5 & 202.6 & 10.1 \\
\hline (SE) & & (3.3) & & (5.6) & (1.7) & (3.1) & (1.6) & (3.3) & (18.2) & $(2.9)$ \\
\hline
\end{tabular}

Table 2. Mean abundances (Individuals $\mathrm{m}^{-2}$; $\mathrm{SE}$ in parentheses) of Caridina nilotica and larval Chaoborus spp. (instars 1-4) collected from different strata by vertical net collections in offshore Lake Victoria. Estimates are based on 4 replicates for each stratum on 24 Oct and 3 replicates on 27 and 28 Oct.

\begin{tabular}{|c|c|c|c|c|}
\hline & Caridina & $m^{-2}$ & Chaoborus & $m^{-2}$ \\
\hline & Night & Day & Night & Day \\
\hline \multicolumn{5}{|l|}{24 Oct 92} \\
\hline $0-10 \mathrm{~m}$ & $1186(70)$ & $5(4)$ & $446(40)$ & $5(3)$ \\
\hline $0-50 \mathrm{~m}$ & & $909(41)$ & & $1001(88)$ \\
\hline \multicolumn{5}{|c|}{$27-28$ Oct 92} \\
\hline $0-20 \mathrm{~m}$ & $125(11)$ & $3(3)$ & $242(72)$ & $75(7)$ \\
\hline $0-40 \mathrm{~m}$ & $648(53)$ & $241(65)$ & $978(17)$ & $757(94)$ \\
\hline
\end{tabular}

$$
\mathrm{DW}=1.429(\mathrm{SE}=0.208) L^{3.021(\mathrm{SE}=0.059)}
$$

Animals used to construct the regression were taken from samples collected 24 October 1992 from the offshore station and ranged in length from 2.3 to $13.8 \mathrm{~mm}$. The empirical ratio for converting Caridina bulk wet mass to dry mass was found to be 0.132 ( $\mathrm{SE}=0.008$; $n=4)$.

\section{Mid-water video transects}

The frequency distributions obtained by counting Caridina in replicate mid-water video fields are consis- tent with a Poisson model, as means are nearly equal to variances in every case (Table 1). Day-time distributions show that the animals are concentrated at depth, with roughly 200 ind. $\mathrm{m}^{-3}$ at $60 \mathrm{~m}$, and less than $2 \mathrm{~m}^{-3}$ at all shallower depths. By contrast, nighttime distributions were more homogeneous through the water column, with a maximum of $c .20$ Caridi$n a \mathrm{~m}^{-3}$ at $20 \mathrm{~m}$ depth. Estimates of total water column abundances can be obtained from data in Table 1 by assuming that the shallowest samples are representative of overlying water, and by using trapezoidal integration of the abundance data down to $60 \mathrm{~m}$. The resulting estimates are $1055(\mathrm{SE}=94)$ Caridina $\mathrm{m}^{-2}$ for the day-time profile and $790(\mathrm{SE}=85) \mathrm{m}^{-2}$ for the night profile, with estimation errors calculated by firstorder error propagation. Any epibenthic Caridina, as well as planktonic individuals deeper than $60 \mathrm{~m}$, are discounted by this calculation.

\section{Bottom video transects}

Estimated abundances for Caridina $\mathrm{m}^{-2}$ on the lake bottom were $166(\mathrm{SE}=13, \mathrm{~N}=114$ quadrant fields) during the day and 81 ( $S E=9, N=119$ quadrant fields) during the night. Underwater video observations revealed that the animals were relatively motionless on the bottom, and that no signs of burrowing were evident. Thus it appeared that the benthic populations were properly quantified. Although animals are significantly more abundant on the bottom during day 
than night, the quantities present on the bottom during the day are only a small fraction (14\%) of total numbers estimated both on the bottom and in the overlying water column (Table 1). At night, only about $9 \%$ of the total Caridina population remains epibenthic.

\section{Net collections}

Diel vertical migration was evident from differences in abundance of both Caridina and Chaoborus in shallow depth strata from day to night (Table 2). Biomass differences between day and night in shallow strata are further amplified from the numerical counts by the fact that the few day-time planktonic Caridina are the smallest juveniles $(2-4 \mathrm{~mm})$, whereas all larger size classes appear to exhibit diel vertical migration. The size range of Caridina collected from shallow depths $(0-20 \mathrm{~m})$ at night encompassed the complete size range of individuals present in the population at the time (Fig. 2). Immature Caridina individuals dominated all offshore collections; of 108 ovigerous females recorded in counts from June and December of 1993, as well as in monthly samples from February to May 1994, only 7 specimens were $13 \mathrm{~mm}$ in length, 1 was $14 \mathrm{~mm}$, and the rest were $15 \mathrm{~mm}$ or larger. Fecundity measured in June 1993 varied with body size, with clutch sizes ranging from $25(13 \mathrm{~mm})$ to $153(17 \mathrm{~mm})$ eggs per female.

Population abundances in different depth strata were contrasted between day or night samplings from October 1992 to June 1994. Sample variances were first homogenized by logarithmic transformation $(\log (\mathrm{N}+1))$ of abundance data. Then, day $v s$ night estimates were compared by independent sample $t$ test, with mean day and/or mean night values from each sampling cruise constituting single estimates for day and/or night abundances. This statistical analysis detected no significant difference between day-time and night-time water column abundances of Caridina when populations were sampled from bottom (nominally $64 \mathrm{~m})$ to surface $(P=0.181)$ or from $60 \mathrm{~m}$ to the surface $(P=0.416)$. By contrast, significant differences were detected for $10-0 \mathrm{~m}$ strata $(P<0.0005)$ and 20-0 m strata $(P<0.0005)$, with day-time abundances at those shallow depths always far less than night-time population levels.

Numerical areal abundances of Caridina collected with the $1 \mathrm{~m}^{2}$ frame net from lake bottom (nominally $64 \mathrm{~m}$ ) to surface and from $60 \mathrm{~m}$ to surface are plotted in Fig. 1. Biomass estimates (Fig. 1) were obtained by multiplying the abundances by the coincident mean
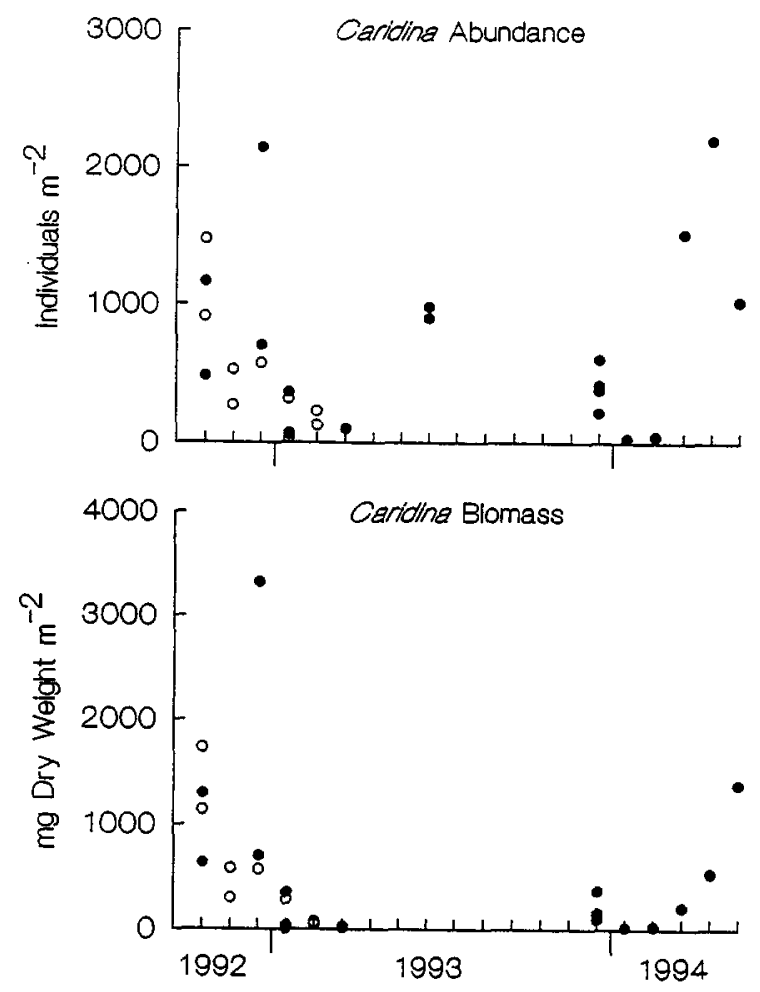

Fig. 1. Abundances and biomasses estimated for Caridina in offshore Lake Victoria from collections made with a $1 \mathrm{~m}^{2}$ frame net. Net tows were from $60 \mathrm{~m}$ to surface (open circles) or from lake bottom (nominally $64 \mathrm{~m}$ ) to surface (filled circles). Size frequency data are lacking for June 1993, and hence biomass was not calculated.

individual dry mass, calculated from empirical size frequency distributions from the same samples, using Eq. 1. Using mean biomass figures calculated for 12 cruises from October 1992 to May 1994, Caridina biomass ranged from 23 to $1536 \mathrm{mg} \mathrm{DW} \mathrm{m}^{-2}$, and averaged $483(\mathrm{SE}=163) \mathrm{mg} \mathrm{DW} \mathrm{m}^{-2}$.

\section{Discussion}

Our evidence for diel vertical migration by Caridina nilotica suggests that visual planktivory may be an important structuring influence on the populations in Lake Victoria. Additional evidence of intense planktivory comes from the size structure of the offshore population over time. Mature, ovigerous females were always rare, and size frequency distributions were truncated near the empirical size of first reproduction $(13 \mathrm{~mm})$. Such preponderance of immature stages in the population at all times, including periods of both 

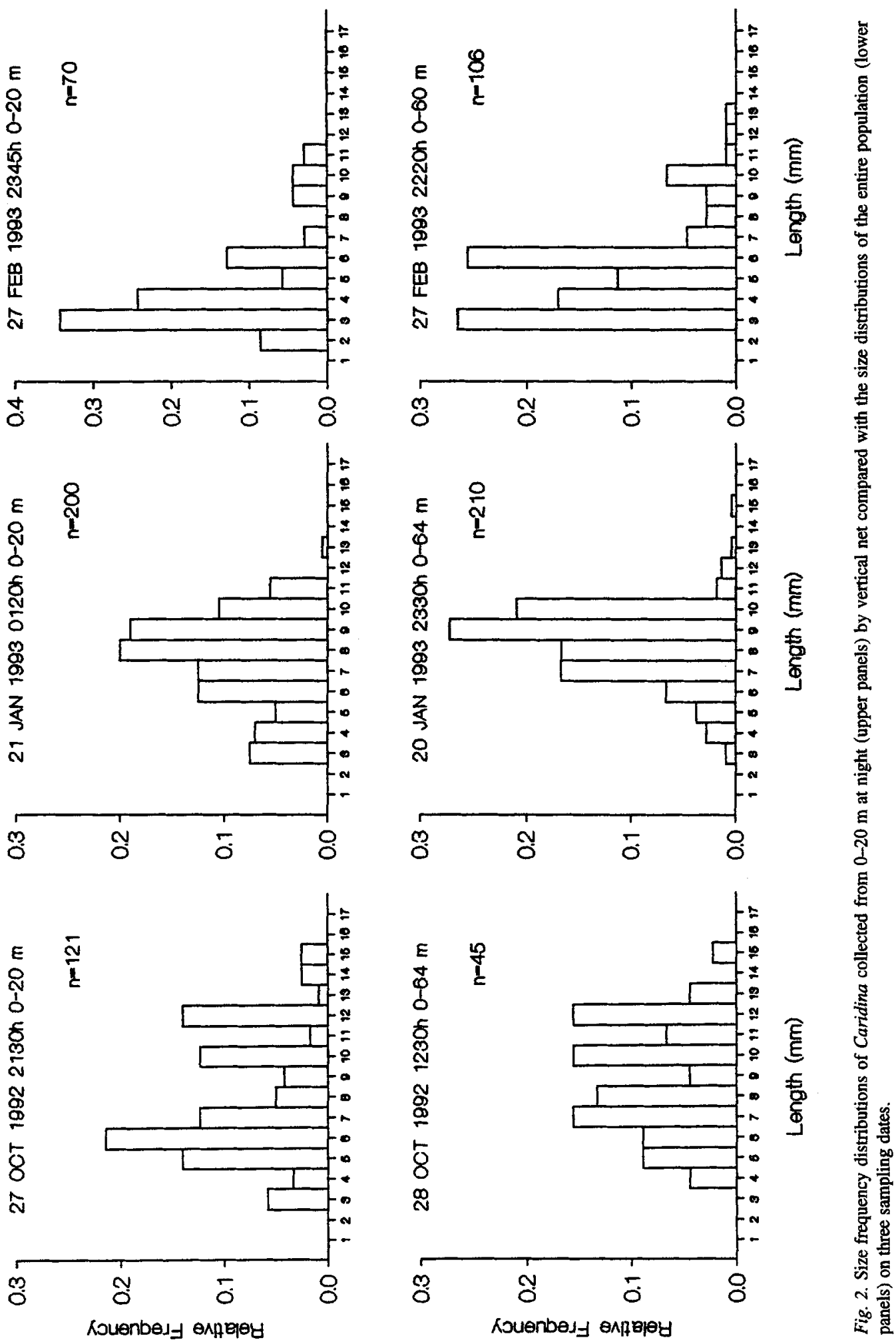
population increase and decrease, suggests that the bulk of the mortality may be concentrated on the largest individuals. Another indication that this is so is that the largest single specimen (among tens of thousands) collected in this study measured only $19 \mathrm{~mm}$, whereas Fryer (1960) had indicated that $25 \mathrm{~mm}$ was a plausible maximum length for the species found among littoral vegetation.

The fact that Fryer (1960) found adult Caridina among littoral vegetation, whereas we find mainly immature animals offshore suggests the possibility of an ontogenetic habitat shift by the species. The juveniles may be pelagic, nocturnal migrators which move to the refuge of macrophyte vegetation nearshore when their increased body size makes them too vulnerable to visual predation. Moreover, it is difficult to conceive why a strict detritivore, which is how Fryer (1960) described Caridina, would migrate upward from the detritus-rich benthos under cover of darkness and thereby incur predation risk. Rather, such behavior is suggestive of facultative planktivores whose access to plankton prey is limited by risk of visual predation from fish. Test of these notions about habitat use and invertebrate planktivory by Caridina invite future experimental investigation of its trophic relationships.

Our two different nets and the video transect methods yielded similar abundance results and concurred that the Caridina population of offshore Lake Victoria is strongly migratory.

The biomass levels we recorded for Caridina represent about $10 \%$ of the reported areal zooplankton biomass for the offshore reference station in Uganda. Lehman \& Branstrator (1993) had reported 2 to $3 \mathrm{~g} \mathrm{C}$ $\mathrm{m}^{-2}$ for the total zooplankton community at this site. Using their conversion of $\mathrm{C}: \mathrm{DW}=0.5$ for zooplankton, Caridina contributes on average about $0.24 \mathrm{~g} \mathrm{C} \mathrm{m}^{-2}$ to this total. Thus Caridina biomass is about 100 -fold lower than the biomass of algae in the offshore region (Lehman \& Branstrator, 1993). The demographics of the population as well as biomass evidence make it seem most likely that offshore populations in Lake Victoria are regulated most strongly by fish predation rather than by food availability.

\section{Acknowledgments}

This research was supported by the University of Michigan Global Change Program and by the NOAA National Undersea Research Program. Dr D. Lee provided operations support for the ROV and collimation apparatus. M. Korell counted most of the mid-water video transects, and $\mathrm{K}$. Thompson counted some of the Caridina net collections. We are grateful to Luc De Meester for suggesting the possibility of ontogenetic shifts in habitat. We thank the captain and crew of the R/V Imputa, as well as the FIRI limnology and fisheries groups for their help with field operations on Lake Victoria.

\section{References}

Beadle, L. C., 1981. The inland waters of tropical Africa. Longman Group Ltd. pp. 475.

Branstrator, D. K., L. M. Ndawula \& J. T. Lehman. Zooplankton dynamics in Lake Victoria. In T. C. Johnson \& E. Odata (eds), Limnology, Climatology and Paleolimnology of the East African Lakes. in press.

Fryer, G., 1960. The feeding mechanism of some atyid prawns of the genus Caridina. Trans. r. Soc. Edin. 64: 217-244

Hughes, N. F., 1992. Nile perch, Lates niloticus, predation on the freshwater prawn, Caridina nilotica, in the Nyanza Gulf, Lake Victoria, East Africa. Envir. Biol. Fishes 33: 307-309.

Lee, D. S. \& D. J. Hall, 1989. Quantitative sampling of organisms/macroparticulates with a ROV using a collimated illumination system, p. 827-831. In Proc. Oceans '89 Tech. Soc., 1719 pp.

Lehman, J. T. \& D. K. Branstrator, 1993. Effects of nutrients and grazing on the phytoplankton of Lake Victoria. Verh. int. Ver. Limnol. 25: 850-855.

Macdonald, W. W., 1956. Observations on the biology of chaoborids and chironomids in Lake Victoria and on the feeding habits of the 'Elephant-Snout Fish' (Mormyrus kannume Forsk). J. anim. Ecol. 25: 36-53.

Mugidde, R., 1993. The increase in phytoplankton primary productivity and biomass in Lake Victoria (Uganda). Verh. int. Ver Limnol. 25: 846-849.

Nero, R. W., 1982. A description of three nets suitable for estimating the abundance of Mysis relicta. Can. Tech. Rep. Fish. aquat. Sci. 1046: iv +8 pp.

Ogutu-Ohwayo, R., 1990. Changes in the prey ingested and the variations in the Nile perch and other fish stocks of Lake Kyoga and the northern waters of Lake Victoria (Uganda). J. Fish Biol. 37: 55-63.

Worthington, E. B., 1931. Vertical movements of freshwater zooplankton. Int. Revue ges. Hydrobiol. Hydrogr. 25: 394-436. 